\section{UF Double Joy Cultivar Group-Five Colors of Double-flowering and Heat-tolerant Lisianthus for Potted Plants}

\author{
Brent K. Harbaugh and Zhanao Deng \\ University of Florida, Institute of Food and Agricultural Sciences, Environmental \\ Horticulture Department, Gulf Coast Research and Education Center, 14625 \\ CR 672, Wimauma, FL 33598
}

Additional index words. high temperature, rosette, potted flowering plants, Eustoma grandiflorum, Gentianaceae, plant breeding

When we started a lisianthus [Eustoma grandiflorum (Raf.) Shinners; Gentianaceae Juss.] breeding program in 1985 at the University of Florida's Gulf Coast Research and Education Center, Bradenton, the emphasis was on development of single flowering, pot or bedding plant types with heat-tolerance and basal branching. At that time, cut flowers with single flowers were the most prominent type of lisianthus being grown in the United States and evaluation of the potential of lisianthus as a pot crop generally was with single flowering types (Halevy and Kofranek, 1984; Roh et al., 1989). Single flowers are still more popular than double flowers in cut-flower markets in Europe and Japan, but double flowers have become the most popular in the U.S. cut-flower markets. Presently, over $80 \%$ of the lisianthus grown for cut flowers in the United States are double flowering types. Double flowers typically have two to five rows of petals compared to a single row with five petals in single flowers. The original double flowers were natural mutations found by Japanese growers (Ohkawa, personal communication). Since double flowering types had such a high acceptance in the United States, we started a program in 1995 to breed our heattolerance into double flowering pot types. High temperatures during the seedling stage cause rosetting in lisianthus (Harbaugh et al., 1992; Harbaugh, 1995; Ohkawa et al., 1991; Ohkawa et al., 1994; Pergola, 1992), and cultivars differ significantly in their sensitivity to high temperatures(Fukuda etal., 1994; Harbaugh etal., 1992; Li et al., 2002). 'Maurine Blue' (Harbaugh and Scott, 1996) and 'Florida Blue' (Harbaugh et al, 1996) were the first heat-tolerant lisianthus whose seedlings could be grown at 28 to $31^{\circ} \mathrm{C}$ without rosetting. The UF Double Joy cultivar group is intermediate in height between the Florida cultivar group and the Maurine cultivar group. Double-flowering types are not yet available in the Maurine and Florida cultivar groups. While a few doubleflowering pot type lisianthus cultivars have recently been released by com-

Received for publication 19 Dec. 2005. Accepted for publication 14 Jan. 2006. This research was supported by the Florida Agricultural Expt. Station. We thank Nancy West and Gail Bowman for their excellent technical support. mercial seed companies in the U.S. market, to our knowledge the UF Double Joy cultivars are the first double flowering and heat-tolerant cultivar group. The UF Double Joy types are represented with five colors including blue, pink, white, blue rim, and pink rim (Fig. 1).

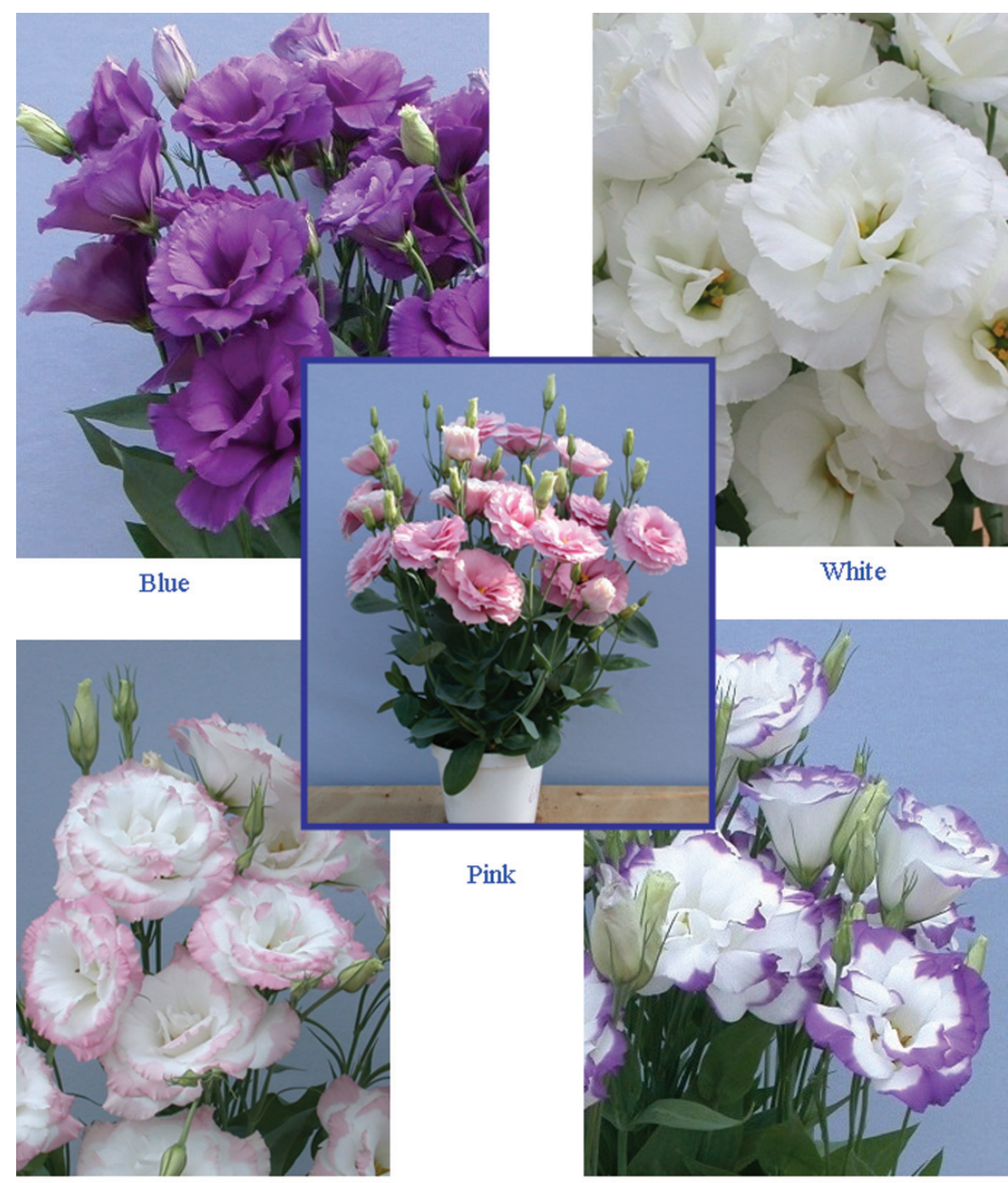

Pink Rim
'UF Double Joy Blue' is an $\mathrm{F}_{1}$ hybrid resulting from crossing inbred lines UF05-887 and UF05-185 (Fig. 2). UF05-887 was used for its large, single dark pink flowers, intermediate plant height, and heat-tolerance. UF05-185 was used for its double blue flowers.

UF05-887 was the $F_{9}$ selection of a cross between UF96-404 and a selection of 'Mariachi Double Pink' (a tall cut-flower). A plant with large pink single flowers was selected in the $\mathrm{F}_{2}$ and inbred seven generations selecting for shorter plants and heat-tolerance. UF96-404 was a semi-dwarf selection of UF95-321 (Harbaugh and Scott, 1999) chosen for its heat-tolerance, bright pink flowers and basal branching. A plant from a population of 'Mariachi Double Pink' was selected for its short height and nice flower form.

UF05-185 was the $\mathrm{F}_{7}$ of a cross between UF96-267 (Harbaugh and Scott, 1996), a very floriferous, basal branching and heat-tolerant line, and UF99-482. UF99-482 was the $\mathrm{F}_{2}$ of UF97-185 and 'Double Echo Pink Picotee' that was used for its double flowers. A blue 
double flowering plant was selected in the $\mathrm{F}_{2}$ that was semi-dwarf.

'UF Double Joy Pink' is an $\mathrm{F}_{1}$ hybrid resulting from crossing inbred lines UF05-798 and UF05-344 (Fig. 2). UF05-798 was used for its large dark pink flowers and intermediate plant height. UF03-782 was used because it had been selected for heat-tolerance and had a double pink flower with excellent flower form.

UF05-798 was the $\mathrm{F}_{8}$ of a cross with UF94-
46 (Harbaugh et al., 1996) selected as a source of heat-tolerance and UF94-226 chosen for its dwarf habit and dark pink flowers. UF94-226 was the $\mathrm{F}_{5}$ of a cross with two dwarf selections of a population of 'Yodel Pink' (tall cut flower).

UF05-344 was the $\mathrm{F}_{9}$ of UF97-185 (the S2 ofUF95-321, see 'UF Double Joy Blue') and a selfing of 'Double Echo Pink Picotee'. UF97185 was used for a source of heat-tolerance and
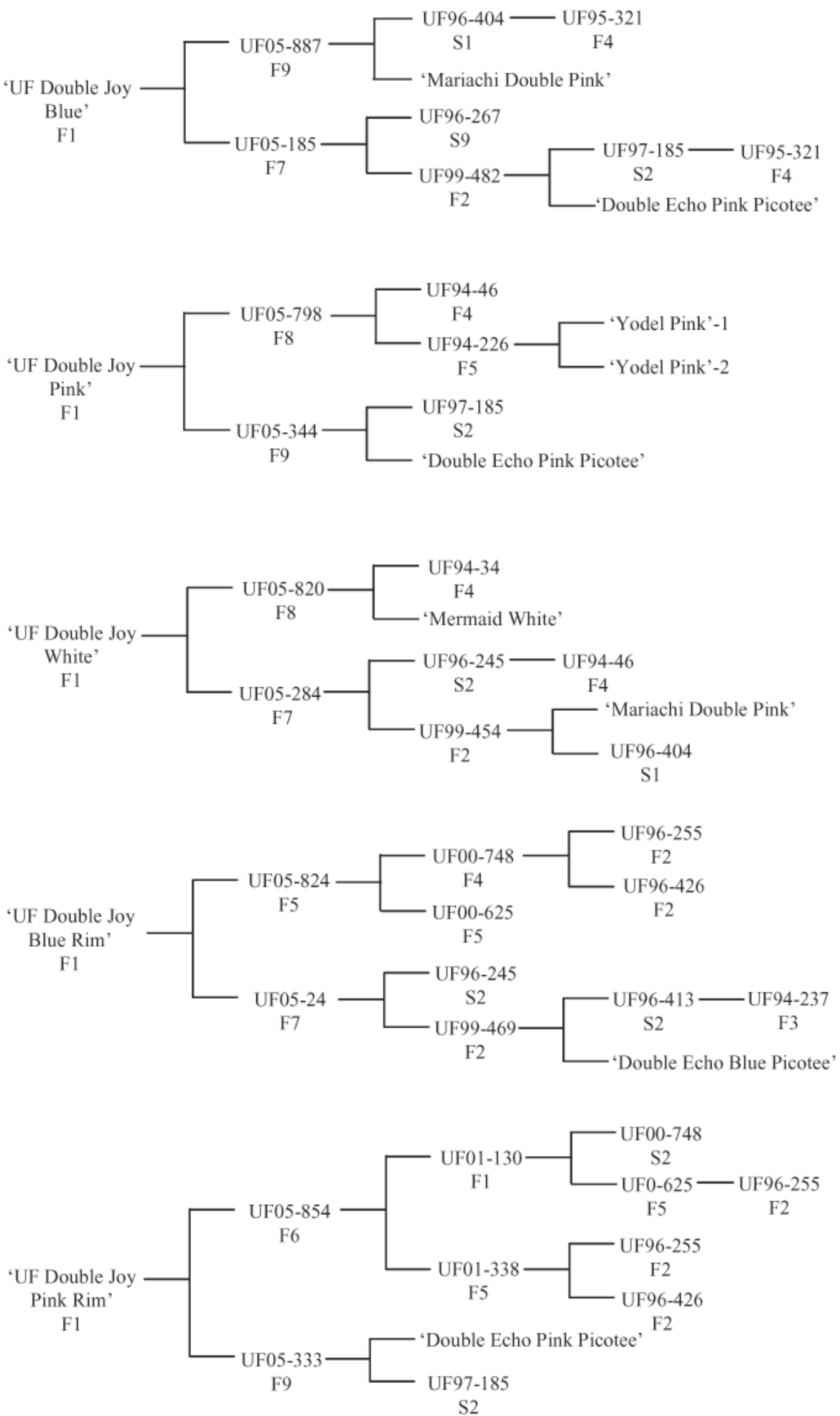

Fig.2. Pedigrees of ‘UF Double Joy Blue', 'UF Double Joy Pink', 'UF Double Joy White', and ‘UF Double Joy Blue Rim', and 'UF Double Joy Pink Rim' F, heat-tolerant lisianthus. dwarf plant habit while 'Double Echo Pink Picotee' was selected for its double flowers.

'UF Double Joy White' is an $\mathrm{F}_{1}$ hybrid resulting from crossing inbred lines UF00877 and UF05-284 (Fig. 2). UF00-877 was chosen for its dwarf habit, sturdy branches and heat-tolerance. UF05-284 was selected for its pure white double flowers and intermediate plant height.

UF00-877 was the $\mathrm{F}_{8}$ selection of a cross between UF94-34 and a selection of 'Mermaid White'. A dwarf plant with white flowers and a green eyespot was selected in the $\mathrm{F}_{2}$ and inbred four generations selecting for shorter plants and heat-tolerance.

UF05-284 was a semi-dwarf selection of UF96-245 and UF99-454. A semi-dwarf plant with white, double flowers and a green eyespot was selected in the $\mathrm{F}_{2}$ and inbred five generations selecting for improved flower form. UF96-245 was the S2 of UF94-46 (Harbaugh et al., 1996) that was used for a source of heat tolerance. UF99-454 was the $F_{2}$ of a cross between a misty pink selection of 'Mariachi Double Pink' (tall cut flower)and UF96-404 (Harbaugh and Scott, 1999). Although both parents were pink, a white, semi-dwarf, double flowering plant was selected in the $\mathrm{F}_{2}$ and served as the source of double flowers.

'UF Double Joy Blue Rim' is an $\mathrm{F}_{1}$ hybrid resulting from crossing inbred lines UF05-824 and UF05-74 (Fig. 2). UF5-824 was chosen for its excellent basal branching, vivid blue rim, and ideal plant height for the UF Double Joy cultivar group. UF05-24 was selected for its double flowers with a pure blue rim.

UF05-824 was the $\mathrm{F}_{5}$ selection of a cross between UF00-748 and UF00-625. UF00-748 was the $\mathrm{F}_{2}$ of a cross between two dwarfblue rim flowers, 96-255 and UF 96-426, both described in Harbaugh and Scott, (2005b). Although UF00-625 had flowers with a pink rim, it was used because of its intermediate height and its pure white color and strong thick rim color. Pink and blue rim flowers sorted out in the $\mathrm{F}_{2}$ and a blue rim selection advanced to the F3.

UF05-24 was the $\mathrm{F}_{7}$ selection of a cross between UF96-245 (see 'UF Double Joy White') and UF99-469. UF99-469 was the $F_{2}$ of a cross between UF96-413 and a selection of 'Double Echo Blue Picotee'. A semi-dwarf plant with double flowers and a blue rim was selected in the $\mathrm{F}_{2}$. UF96-413 was the S2 of UF94-237 (Harbaugh and Scott, 2005a) used for its heattolerance and basal branching.

'UF Double Joy Pink Rim' is an $\mathrm{F}_{1}$ hybrid resulting from crossing inbred lines UF05-854 and UF05-333 (Fig. 2). UF05-854 was chosen for its excellent basal branching, vivid pink rim, and heat-tolerance. UF05-333 was selected for its double flowers with a pink rim.

UF05-854 was the $\mathrm{F}_{6}$ of a cross between UF01-130 and UF01-338. UF01-130 was selected for its plant habit and earliness to flower, and although its flower had a blue rim, it had a recessive gene for pink rim color. UF01-130 was the $F_{1}$ of UF00-748 and UF00625 (Harbaugh and Scott, 2005a). UF00-748 was the S2 of UF96-255 (Harbaugh and Scott, 2005 b), a dwarf plant with blue rim flowers. UF00-625 was intermediate in height and 
Table 1. Percentage rosetted plants $\mathrm{s}^{\mathrm{z}}$ and growth and flowering characteristics ${ }^{\mathrm{y}}$ of twelve cultivars of lisianthus grown in 11.5 -cm square pots $(0.65$-L) at Bradenton, Fla.

\begin{tabular}{|c|c|c|c|c|c|c|c|}
\hline \multirow[b]{2}{*}{ Cultivar } & \multicolumn{4}{|c|}{ Plant $^{x}$} & \multirow{2}{*}{$\begin{array}{c}\text { Flowers } \\
\text { and buds } \\
\text { (no.) }\end{array}$} & \multirow{2}{*}{$\begin{array}{l}\text { Petal } \\
\text { length } \\
(\mathrm{cm})\end{array}$} & \multirow{2}{*}{$\begin{array}{l}\text { Days to } \\
\text { flower } \\
\text { (no.) }\end{array}$} \\
\hline & $\begin{array}{c}\text { Rosetted } \\
(\%)\end{array}$ & $\begin{array}{l}\mathrm{Ht} \\
(\mathrm{cm})\end{array}$ & $\begin{array}{l}\text { Width } \\
\text { (cm) }\end{array}$ & $\begin{array}{c}\text { Branches }^{w} \\
\text { (no.) }\end{array}$ & & & \\
\hline Florida Silver & 0 & 37 & 23 & 11 & 80 & 6.2 & 114 \\
\hline Lizzy Pink & 100 & 31 & 20 & 8 & 54 & 5.6 & 116 \\
\hline Mermaid Lilac Rose & 97 & 28 & 18 & 8 & 55 & 5.8 & 112 \\
\hline Sapphire Blue Chip & 83 & 28 & 19 & 11 & 66 & 5.5 & 107 \\
\hline UF Double Joy Blue Rim & 0 & 38 & 20 & 11 & 59 & 5.6 & 116 \\
\hline UF Double Joy Pink & 0 & 55 & 16 & 8 & 38 & 5.9 & 116 \\
\hline UF Double Joy Pink Rim & 0 & 44 & 23 & 8 & 49 & 5.9 & 119 \\
\hline UF Double Joy White & 0 & 39 & 23 & 10 & 67 & 5.6 & 115 \\
\hline $\operatorname{LSD}(\%=0.05)$ & 11 & 3.5 & 4.7 & 2.1 & 9.2 & 0.4 & 3 \\
\hline
\end{tabular}

${ }^{2}$ Seventeen-day-old seedlings were exposed to $31{ }^{\circ} \mathrm{C}$ for 5 weeks in a growth chamber and then grown in a greenhouse for 4 weeks. Percentages of rosetted plants are means of three replications with eight plants as the experimental unit arranged in a randomized block design.

${ }^{y}$ Vegetative and flowering characteristics were for plants grown in a greenhouse at 33 to $35^{\circ} \mathrm{C}$ day and 13 to $15{ }^{\circ} \mathrm{C}$ night. Values are means of five replications of single-plant experimental units arranged in a completely randomized design.

${ }^{x}$ Plant height $=$ distance from the pot rim to the tip of the highest bud measured after three flowers had opened.

w Lateral stems forming on the central stem from the basal leaves to the first flower.

served as a source for flowers with a vivid pink rim. UF01-338 was the $\mathrm{F}_{5}$ of UF96-255 and UF96-426, both dwarf plants with flowers having very dark pink rims.

UF05-333 was the $F_{9}$ of 'Double Echo Pink Picotee' and UF97-185. A semi-dwarf plant with double, pink rim flowers was selected in the $\mathrm{F}_{2}$ and inbred seven generations selecting for improved flower form and color. A plant from a population of 'Double Echo Pink Picotee' was used as a source for double flowers and UF97-185 (Harbaugh and Scott, 1999) for heat-tolerance and dwarf plant habit.

Growing conditions used to select seedlings for resistance to heat-induced rosetting during development of heat tolerant parents included: (1) production during summer months under greenhouse conditions at day temperatures $\geq 35$ ${ }^{\circ} \mathrm{C}$, (2) exposure of 2- to 4-week-old seedlings to $28^{\circ} \mathrm{C}$ for 4 weeks in a growth chamber for initial selections in early generations, and (3) exposure of 17 -d-old seedlings to $31{ }^{\circ} \mathrm{C}$ in a growth chamber for 5 weeks for selection of final parents used in $\mathrm{F}_{1}$ hybrids. The photosynthetic photon flux in growth chambers was 150 to $190 \mu \mathrm{mol} \cdot \mathrm{m}^{-2} \cdot \mathrm{s}^{-1}$ from cool-white fluorescent bulbs.

\section{Flower Color Description}

Flower color was determined under natural light using the Royal Horticultural Society Colour Chart (Royal Horticultural Society, 1966). A number plus a letter are used for each color chip (e.g., 155D). Petals of lisianthus typically are one color over most of the surface, but exhibit a distinct basal eyespot (i.e., base of petals surrounding the ovary) of a different color.

'UF Double Joy Blue' flower petals are a violet blue (90C) on the adaxial petal surface. As the flower matures, the petal color darkens to dark purple (79A). The abaxial petal surface is a lighter violet (90D) and then darkens to purple (86B) as the flower matures. The eye spot is dark purple (79A).

'UF Double Joy Pink' petals are light pink
(65A) on the adaxial surface. The abaxial surface is lighter pink (65D). The eyespot is dark red-purple (61A).

'UF Double Joy White' flower petals are white (155D) on the adaxial and abaxial petal surfaces. The eyespot is a yellow-green (145B).

'UF Double Joy Blue Rim' and 'UF Double Joy Pink Rim 'flower petals are predominantly white (155D) on the adaxial and abaxial petal surface. 'UF Double Joy Blue Rim' flowers have a violet-blue ( $89 \mathrm{C}$ on the adaxial and lighter violet blue $90 \mathrm{C}$ on the abaxial) petal surface border of the petal apex that is usually 0.5 to 0.75 cm wide. 'UF Double Joy Pink Rim' flowers have a dark pink (55C on the adaxial and 56A on the abaxial petal surface) border on the petal apex. The eyespot is a yellow-green (145B) on both cultivars.

\section{Characteristics and Use}

Heat tolerance as well as vegetative and flower characteristics of the Double Joy cultivar group were compared to seven commercial bedding or pot type cultivars. Seeds of all cultivars were planted on 19 Jan. 2005, at Bradenton, Fla. Seventeen-d-old seedlings were grown either in a glasshouse (control) with a high of 30 to $33^{\circ} \mathrm{C}$ day and 13 to 15 ${ }^{\circ} \mathrm{C}$ night or at a constant $31{ }^{\circ} \mathrm{C}$ for 5 weeks in a growth chamber (heat-stressed). Seedlings exposed to $31^{\circ} \mathrm{C}$ were rated as rosetted if they had not bolted after growth for an additional 4 weeks in the control greenhouse. Nonrosetted plants from the control greenhouse were evaluated for plant height, plant width, number of branches (lateral stems forming on the central stem from the basal leaves to the first flower), total number of flowers and buds per plant after three flowers were open, petal length, and the number of days from sowing to flowering.

The most important and distinguishing attribute of all the Double Joy cultivar-group cultivars as compared with other commercial lines was their heat tolerance (Table 1). 'Florida Silver' was an exception but it was released from our program as a semi-dwarf and heattolerant line and is now commercialized (Harbaugh et al., 1996). None of the heat stressed Double Joy cultivar group rosetted while 70\% 'Forever White', 97\% 'Lisa Lavender', 100\% 'Lizzy Pink', 97\% ‘Mermaid Lilac Rose', 86\% 'Sapphire Blue Chip', and 53\% 'Tiramisu Double Violet' seedlings rosetted.

In addition to heat tolerance, we considered that the UF Double Joy cultivars exhibited sufficient similarities in flower form and display, branching habit, and in the number of days from sowing to flowering to be included in the Double Joy cultivar-group. Notable differences were that plant height ranged from 38 to $48 \mathrm{~cm}$ for all UF Double Joy cultivars except 'UF Double Joy Pink' that was $55 \mathrm{~cm}$, and 'UF Double Pink Rim' flowered 119 days from sowing compared to 115 to $116 \mathrm{~d}$ for the other UF Double Joy cultivars.

UF Double Joy cultivars are intended to be used as flowering potted plants in containers $\geq$ 15-cm-diameter pots. Plant height for Maurine cultivars averaged 75 to $102 \mathrm{~cm}$ (Harbaugh and Scott, 1998) and Florida cultivars 28 to $35 \mathrm{~cm}$ (Harbaugh and Scott, 2001). Thus the UF Double Joy cultivars were intermediate in height averaging 39 to $55 \mathrm{~cm}$. Treatment with growth retardants is necessary for production of UF Double Joy cultivars in $\leq 15$-cm-diameter pots (Harbaugh etal., 1998). Three to four plugs per 15-cm-diameter pot are recommended for optimal marketing display.

\section{Availability}

Distribution of seed is through the Florida Foundation Seed Producers, P.O. Box 309, Greenwood, FL 332443. Scientists interested in small amounts of seed for research purposes should contact B.K.H.

\section{Literature Cited}

Fukuda, Y., K. Ohkawa, K. Kanematsu, and M. Korenga. 1994. Classification of Eustoma grandiflorum (Raf.) Shinn. cultivars on rosette characteristics based on the bolting ratios after 
a high temperature treatment. J. Jpn. Soc. Hort. Sci. 62:845-856.

Halevy, A.H. And A.M. Kofranek. 1984. Evaluation of lisianthus as a new flower crop. HortScience 19:845-847.

Harbaugh, B.K. 1995. Flowering of Eustoma grandiflorum (Raf.) Shinn. cultivars influenced by photoperiod and temperature. HortScience 30:1375-1377.

Harbaugh, B.K., M.S. Roh, R.H. Lawson, and B. Pemberton. 1992. Rosetting of lisianthus cultivars exposed to high temperatures. HortScience 27:885-887.

Harbaugh, B.K. and J.W. Scott. 1996. 'Maurine Blue' lisianthus [Eustoma grandiflorum (Raf.) Shinn.]. HortScience 31:1055-1056.

Harbaugh, B.K. and J.W. Scott. 1999. 'Florida Pink' and 'Florida Light Blue'-Semi-dwarf heat-tolerant cultivars of lisianthus. HortScience
34:364-365.

Harbaugh, B.K. and J.W. Scott. 2005a. 'Maurine Dawn'-A heat-tolerant lisianthus with pink/white bicolored flowers. HortScience 40:858-860.

Harbaugh, B.K. and J.W. Scott. 2005b. 'Florida Blue Frill' and 'Florida Pink Frill'-Semi-dwarf heat-tolerant lisianthus with bicolored flowers. HortScience 40:861-863.

Harbaugh, B.K., J.W. Scott, and D.B. Rubino. 1996. 'Florida Blue' semi-dwarf lisianthus [Eustoma grandiflorum (Raf.) Shinn.]. HortScience 31:1057-1058.

Li, J., Y. Notsu, M. Ogawa, H. Ohno, and K. Ohkawa. 2002. Rosetting characteristics-based on classification of Eustoma grandiflorum (Raf.) Shinn. cultivars sown on different dates. (Japanese text with English abstract) Environ. Control Biol 40:229-237.
Ohkawa, K., A. Kano, K. Kanematsu, and M. Korenaga. 1991. Effects of air temperature and time on rosette formation in seedlings of Eustoma grandiflorum (Raf.) Shinn. Scientia Hort. 48:171-176.

Ohkawa, K., T. Yoshizumi, M. Korenaga, and K. Kanematsu. 1994. Reversal of heat-induced rosetting in Eustoma grandiflorum with low temperatures. HortScience 29:165-166.

Pergola, G. 1992. The need for vernalization in Eustoma russellianum. Scientia Hort. 51:123-127.

Roh, M.S., A.H. Halevy, and H.F. Wilkins. 1989. Eustoma grandiflorum, p 322-327. In A.H. Halevy (ed.). Handbook of flowering. vol. VI. CRC Press, Boca Raton, Fla.

Royal Horticultural Society. 1966. Royal Horticultural Society colour chart. Royal Hort. Soc., London. 